\title{
The Relationship between Central Retinal Artery Resistive Index and Measures of Renal Function in Type 2 Diabetes
}

\author{
0. O. Ayoola ${ }^{1}$, D. O. Soyoye ${ }^{2}$, S. D. Dawha ${ }^{1}$, R. T. Ikem², O. H. Onakpoya ${ }^{3}$, T. A. Adedeji ${ }^{4}$, \\ F. A. Arogundade ${ }^{2}$ \\ ${ }^{1}$ Department of Radiology, Obafemi Awolowo University, Ile-Ife, Nigeria \\ ${ }^{2}$ Department of Medicine, Obafemi Awolowo University, Ile-Ife, Nigeria \\ ${ }^{3}$ Department of Ophthalmology, Obafemi Awolowo University, Ile-Ife, Nigeria \\ ${ }^{4}$ Department of Chemical Pathology, Obafemi Awolowo University, Ile-Ife, Nigeria \\ Email: *oluyoola@gmail.com
}

Received 10 February 2016; accepted 3 May 2016; published 6 May 2016

Copyright (C) 2016 by authors and Scientific Research Publishing Inc.

This work is licensed under the Creative Commons Attribution International License (CC BY). http://creativecommons.org/licenses/by/4.0/

(c) (i) Open Access

\section{Abstract}

Background: Renal and ocular vessels are some of the major vessels affected in patients with diabetes, and the involvement of these vessels is independent risk factors for other complications. Hemodynamic flow in arteries may be assessed by using measures such as resistive index, which is a non-invasive measure of the resistance in vessels. The association between retinopathy and nephropathy has been conflicting. This study assessed the relationship between resistive index of the central retinal artery and indices of nephropathy in type 2 diabetes. Method: This cross-sectional study examined 74 Nigerian diabetics who were selected consecutively from the out-patient diabetic clinic of a tertiary hospital in South-West Nigeria. Doppler ultrasound was used to determine the resistive index of the central retinal artery along with the right renal artery. The urinary and serum biochemical parameters were also done to determine the urinary albumin excretion and the glomerular filtration rate. Results: The mean age of participants was $59.62 \pm$ 9.55 years. The mean central retinal artery resistive index (CRARI) was $0.77 \pm 0.06$, with 65 (87.8\%) of the participants having elevated CRARI. There was no statistical difference between patients with normal CRARI and elevated CRARI in respect of their urinary albumin excretion (p = 0.796). There was no significant correlation between CRARI and estimated glomerular filtration rate $(r=0.120 ; p=0.309)$ and right renal artery resistive index $(r=0.068 ; p=0.564)$. Conclusion: This study demonstrates that central retinal artery resistive index (CRARI) may not be a predictor of renal function in diabetics.

*Corresponding author.

How to cite this paper: Ayoola, O.O., Soyoye, D.O., Dawha, S.D., Ikem, R.T., Onakpoya, O.H., Adedeji, T.A. and Arogundade, F.A. (2016) The Relationship between Central Retinal Artery Resistive Index and Measures of Renal Function in Type 2 Diabetes. Journal of Diabetes Mellitus, 6, 146-151. http://dx.doi.org/10.4236/jdm.2016.62015 


\section{Keywords}

\section{Ultrasound, Retinal Artery, Renal Function}

\section{Introduction}

Diabetes is a metabolic disorder with multi-systemic affectation. Most of the complications of diabetes arise as a result of its effects on both macrovascular and microvascular vessels. Involvement of the ocular and renal microvessels may result in diabetic retinopathy and nephropathy respectively with attendant disability, economic burden and death. If diagnosed early, complications resulting from involvement of these vessels could be preventable, thereby reducing other cardiovascular events [1] [2]. In a review of results from the Nigeria national blindness and visual impairment survey, prevalence of diabetic retinopathy was $20.5 \%$ [3]. Rotimi et al. [4] reported a diabetic retinopathy prevalence of $17.3 \%$ among cohorts of diabetic patients in Nigeria. Prevalence of diabetic retinopathy has been reported to be between $16 \%$ and $55 \%$ in Africa [5]. Prevalence of microalbuminuria as a measure of diabetic nephropathy has been reported to be between $10 \%$ and $57 \%$ in Africans with type 2 diabetes [5].

There have been reports of association between diabetic retinopathy and measures of nephropathy [6]-[8]. Prakash et al., however, noted that diabetic retinopathy does not predict diabetic nephropathy in type 2 patients [9]. The association between ocular vascular resistance using resistive index and measures of chronic kidney disease and/or renal vascular resistance has been examined previously [10]. The usefulness of measurement of ocular resistive index as a measure of vascular resistance is not fully understood [11]. However, ocular vascular evaluations may be an accessible measure for early detection of both retinal and renal dysfunctions. Ultrasonography is a non-invasive, relatively inexpensive and readily available investigation. This study determined the relationship between central retinal artery resistive index (CRARI) and right renal artery resistive index (RRARI) and measures of nephropathy (albuminuria, glomerular filtration rates) in type 2 diabetes patients.

\section{Patients and Methods}

This cross-sectional study involved consecutive patients with Type 2 Diabetes Mellitus recruited from the Diabetes clinic from June 2012 to May 2013. The Diabetes clinic is an out-patient clinic in the hospital premises that operates weekly with patients' attendance of 100 - 120 people per clinic day. Ethical approval was granted by the Ethics and Research committee of the institution. Informed consent was sought and granted by all the participants. Participants with glaucoma and other conditions like ocular injury and conjunctivitis that could make Doppler assessment of the central retinal artery difficult were excluded by the Opthalmologist. Participants with recent febrile illness and other acute medical conditions were also excluded. Relevant history was taken and clinical examination done. Blood samples were taken to determine the serum fasting plasma glucose, total cholesterol, low-density lipoprotein, high-density lipoprotein, triglycerides, serum creatinine. Urinary albumin-creatinine ratio (UACR) of a random spot urine was determined using CLINITEK microalbumin (Siemens Healthcare Inc, Camberly, UK), a semi-quantitative strip test. UACR was calculated as albumin ( $\mu \mathrm{g}) /$ creatinine $(\mathrm{g})$. Normoalbuminuria, microalbuminuria and macroalbuminuria was defined using UACR of $<30$ $\mu \mathrm{g} / \mathrm{mg}, 30-300 \mu \mathrm{g} / \mathrm{mg}$ and $>300 \mu \mathrm{g} / \mathrm{mg}$ respectively [12]. Estimated glomerular filtration rate (eGFR) was calculated using the Cockroft-Gault formula [13] and this was used to stage kidney function into stage $1(\geq 90$ $\mathrm{mls} / \mathrm{min})$; stage 2 (60 - $89 \mathrm{mls} / \mathrm{min})$; stage 3 (30 - $59 \mathrm{mls} / \mathrm{min})$; stage 4 (15 - $29 \mathrm{mls} / \mathrm{min})$; stage $5(<15 \mathrm{mls} / \mathrm{min})$. The formula is as follows:

$$
C_{c r}=\frac{(140-\text { Age }) \times \text { Weight }(\mathrm{kg})}{72 S_{c r}}
$$

The value obtained is multiplied by 0.85 in women.

$C_{c r}=$ Creatinine clearance; $S_{c r}=$ Serum creatinine $(\mathrm{mg} / \mathrm{dL})$

Doppler ultrasound scan of the right central retinal and right renal arteries was done using a Mindray DC-7 ultrasound machine and the resistive indices of the vessels calculated from the formula [11]: 


$$
\mathrm{RI}=\frac{\mathrm{PSV}-\mathrm{EDV}}{\mathrm{PSV}}
$$

where PSV = Peak systolic flow velocity; EDV = End-diastolic flow velocity.

Resistive index of $>0.70$ was considered elevated [10]. Data was inputted into a personal computer and analysed using the statistical software package SPSS version 20 (IBM Corp Released 2011. IBM SPSS Statistics for Windows, Version 20.0, Armonk, NY). Significant differences between continuous variables were assessed using Student's $\mathrm{t}$ test, while chi square test $\left(\chi^{2}\right)$ was used to determine differences between categorical variables. Correlation analysis was done to determine the relationship between central retinal resistive index and other metric variables. $p$ value of $<0.05$ was taken to be statistically significant.

\section{Results}

Seventy-four type 2 diabetic patients consisting of 32 males and 42 females. Mean age of study population was $59.62 \pm 9.55$ years (male: $59.66 \pm 9.57$ vs female: $59.60 \pm 9.65 ; \mathrm{p}=0.978$ ). Table 1 shows the clinical and laboratory parameters in the study population.

Sixty five (87.8\%) participants had elevated CRARI, with more females $36(55.4 \%)$ having elevated CRARI compared with males $29(44.6 \%)(\mathrm{p}=0.723)$. Mean CRARI in the study participants was $0.77 \pm 0.06$ (male: $0.77 \pm 0.05$; female: $0.78 \pm 0.07, \mathrm{p}=0.430)$. Of the participants with elevated CRARI, $9(13.8 \%), 29(44.6 \%)$ and $27(41.6 \%)$ had macroalbuminuria, microalbuminuria and normoalbuminuria respectively $(p=0.159)$. Table 2 shows the differences between participants with normal CRARI and those with elevated CRARI.

Eleven $(14.9 \%)$ participants had macroalbuminuria (male-4 (5.4\%) vs female-7(9.5\%); and $30(40.5 \%)$ had microalbuminuria (male-12 $(16.2 \%)$ vs female-18 $(24.3 \%)(p=0.701)$. Figure 1 shows the relationship between central retinal artery resistive index and stages of chronic kidney disease among participants.

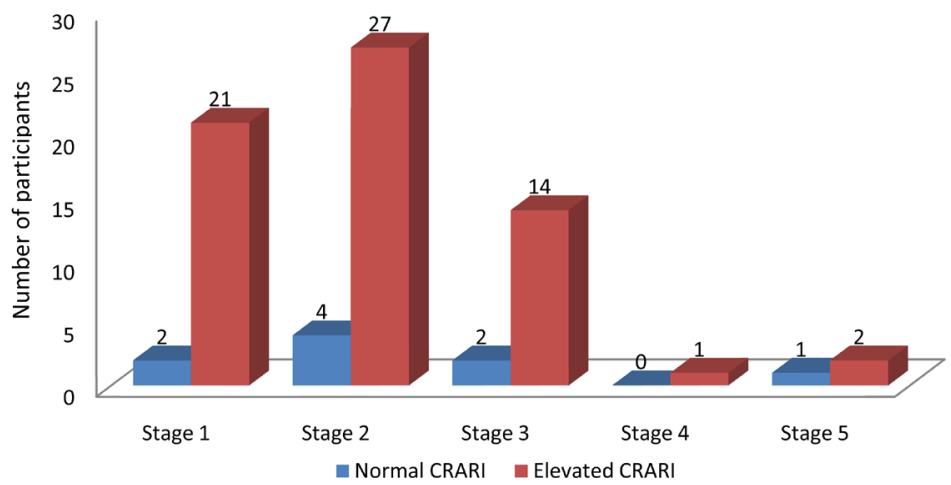

Figure 1. A clustered bar chart showing a frequency distribution based on CRARI normalcy and stages of chronic kidney disease using the Cockroft gault equation among study participants. $X^{2}=1.674 ; \mathrm{df}=4 ; \mathrm{p}=0.796$.

Table 1. A table showing the clinical and laboratory parameters among study participants by gender.

\begin{tabular}{|c|c|c|c|}
\hline Characteristic & Male $($ mean $\pm \mathrm{SD}) \mathrm{N}=32$ & Female $($ mean $\pm \mathrm{SD}) \mathrm{N}=4$ & $\mathrm{p}$ value \\
\hline Duration of diabetes (years) & $8.76 \pm 6.72$ & $8.08 \pm 6.90$ & 0.665 \\
\hline Body mass index $\left(\mathrm{kg} / \mathrm{m}^{2}\right)$ & $25.72 \pm 4.27$ & $28.76 \pm 5.79$ & 0.011 \\
\hline $\mathrm{SBP}(\mathrm{mmHg})$ & $132.19 \pm 17.22$ & $130.64 \pm 19.58$ & 0.720 \\
\hline DBP (mmHg) & $77.38 \pm 9.19$ & $76.38 \pm 9.34$ & 0.649 \\
\hline eGFR (mls/min) & $88.17 \pm 48.68$ & $72.20 \pm 30.86$ & 0.461 \\
\hline FPG (mmol/L) & $7.44 \pm 1.85$ & $7.44 \pm 1.78$ & 0.976 \\
\hline $\mathrm{TC}(\mathrm{mmol} / \mathrm{L})$ & $4.12 \pm 1.00$ & $4.34 \pm 0.97$ & 0.411 \\
\hline HDL (mmol/L) & $1.23 \pm 0.52$ & $1.21 \pm 0.57$ & 0.818 \\
\hline $\mathrm{TG}(\mathrm{mmol} / \mathrm{L})$ & $1.31 \pm 1.07$ & $1.07 \pm 0.41$ & 0.132 \\
\hline LDL (mmol/L) & $2.44 \pm 1.13$ & $2.62 \pm 0.79$ & 0.478 \\
\hline RRARI & $0.72 \pm 0.06$ & $0.73 \pm 0.07$ & 0.698 \\
\hline
\end{tabular}

SPB — Systolic blood pressure; DBP_-Diastolic blood pressure; eGFR — estimated glomerular filtration rate; FPG — Fasting plasma glucose; TCTotal cholesterol; HDL — high density lipoprotein; TG-Triglycerides; LDL-Low density lipoprotein; RRARI—right renal artery resistive index. 
Table 2. A table showing a comparison of mean values of demographic, clinical and biochemical parameters in participants with normal and elevated central retinal artery resistive index.

\begin{tabular}{|c|c|c|c|}
\hline Parameter & Normal CRARI $(\mathrm{N}=9)$ & Elevated CRARI $(\mathrm{N}=65)$ & $\mathrm{p}$ value \\
\hline Age (years) & $60.22 \pm 11.04$ & $59.54 \pm 9.41$ & 0.863 \\
\hline Body mass index $\left(\mathrm{kg} / \mathrm{m}^{2}\right)$ & $29.91 \pm 4.19$ & $27.11 \pm 5.46$ & 0.096 \\
\hline Systolic BP (mmHg) & $130.89 \pm 20.42$ & $131.37 \pm 18.38$ & 0.948 \\
\hline Diastolic BP (mmHg) & $77.89 \pm 4.54$ & $76.66 \pm 9.71$ & 0.533 \\
\hline eGFR $\left(\mathrm{ml} / \mathrm{min} / 1.73 \mathrm{~m}^{2}\right)$ & $67.24 \pm 31.01$ & $80.75 \pm 41.08$ & 0.263 \\
\hline FBS $(\mathrm{mmol} / \mathrm{L})$ & $6.83 \pm 1.09$ & $7.53 \pm 1.87$ & 0.126 \\
\hline $\mathrm{TC}(\mathrm{mmol} / \mathrm{L})$ & $3.92 \pm 1.23$ & $4.30 \pm 0.95$ & 0.425 \\
\hline $\mathrm{HDL}(\mathrm{mmol} / \mathrm{L})$ & $1.19 \pm 0.73$ & $1.22 \pm 0.52$ & 0.910 \\
\hline $\mathrm{TG}(\mathrm{mmol} / \mathrm{L})$ & $1.54 \pm 1.68$ & $1.07 \pm 0.57$ & 0.451 \\
\hline $\mathrm{LDL}(\mathrm{mmol} / \mathrm{L})$ & $2.23 \pm 0.76$ & $2.56 \pm 0.97$ & 0.494 \\
\hline RRARI & $0.73 \pm 0.09$ & $0.72 \pm 0.06$ & 0.090 \\
\hline
\end{tabular}

SPB — Systolic blood pressure; DBP—Diastolic blood pressure; eGFR—estimated glomerular filtration rate; FPG—Fasting plasma glucose; TC — Total cholesterol; HDL — high density lipoprotein; TG - Triglycerides; LDL — Low density lipoprotein; RRARI-right renal artery resistive index.

There was no significant correlation between CRARI and eGFR $(r=0.120 ; \mathrm{p}=0.309)$,duration of diabetes $(\mathrm{r}$ $=-0.081, \mathrm{p}=494)$, body mass index $(\mathrm{r}=-0.017 ; \mathrm{p}=0.884)$, systolic blood pressure $(\mathrm{r}=0.027 ; \mathrm{p}=0.819)$, fasting plasma glucose $(\mathrm{r}=-0.112 ; \mathrm{p}=342)$, total cholesterol $(\mathrm{r}=-0.003 ; \mathrm{p}=0.978)$, serum high-density lipoprotein $(\mathrm{r}=-0.162 ; \mathrm{p}=0.169)$, serum triglycerides $(\mathrm{r}=-0.046 ; \mathrm{p}=0.710)$, serum low-density lipoprotein $(\mathrm{r}=$ $0.027 ; \mathrm{p}=0.836)$ or RRARI $(\mathrm{r}=0.068 ; \mathrm{p}=0.564)$.

\section{Discussion}

Hyperglycemia selectively damages the endothelial cells of the retina, glomerulus and neurons, with shared pathologic characteristics in the development of these diabetic complications [14] [15]. Sustained hyperglycemia results in polyol accumulation, formation of advanced glycation end products (AGEs), oxidative stress, and activation of protein kinase $\mathrm{C}$ (PKC), which are pathway postulated to be responsible for microvascular complications in diabetes [14] [16]. Resistive index assessment in the central retinal artery is a measure of increased resistance in this vessel, which is suggested to contribute to diabetic retinopathy. Assessment of central retinal artery resistive index may be an early marker of overt diabetic retinopathy [17].

In this study, mean central retinal artery resistive index was $0.77 \pm 0.06$. This is similar to that obtained by Amin et al. [2], who reported mean CRARI of $0.75 \pm 0.04$ in patients with type 2 diabetes without retinopathy, which was significantly higher compared with controls. Most of the patients with elevated CRARI were in the early stages of chronic kidney disease. Mean systolic blood pressure, estimated glomerular filtration rate, fasting blood glucose, total cholesterol, high density lipoprotein and low-density lipoprotein were higher in patients with elevated CRARI compared with patients with normal CRARI, but values were not statistically significant (Table 2).

This study was conducted to ascertain the association between resistive index of the right central retinal artery and measures of renal function, for a possible early detection of renal microvascular involvement in diabetes. There was no correlation between central retinal artery resistive index and glomerular filtration rate and resistive index of the right renal artery.

Resistive index has been regarded as a measure of vascular resistance; however some studies [18] [19] have suggested that resistive index is not only a measure of vascular resistance, but of impedance, which is a measure of both vascular resistance and vascular compliance. Vascular compliance, defined as change in vascular volume with change in vascular pressure [11] [18], has profound individual variability even when the vascular resistance is constant [18] [19]. In effect, the resistive index would vary depending on the compliance of the vessel. This variability may explain the lack of association between central retinal artery resistive index and the measures of renal function studied. Our finding may also suggest that the pathogenic mechanism for resistance in the ocular vessels may be different from that responsible for nephropathy in patients with type 2 diabetes mellitus. 
It is acknowledged that estimation of urinary protein excretion over a 24-hr period is the gold standard method due to a high degree of variation in the urinary protein concentration during the course of the day [20]; this approach however would have been impractical to undertake as it would have been impracticable for the greater majority of subjects recruited for the study. Nevertheless statistically significant values with correlations as high as 0.98 [21] have been reported for ratio of protein: creatinine on a spot urine sample with 24-hr urine collection sample.

\section{Conclusions}

The small size of our study may limit its interpretation to the general population. Glycated hemoglobin, a long term measurement of glycemia was not measured in our participants. Despite these limitations, this study is crucial in recognizing the lack of association between measure of resistance of ocular vessels and measures of stages of renal dysfunction. Additionally, to the best of our knowledge, this is the first study that considers the possible association between resistive index in ocular vessels (using the central retinal artery) and diabetic nephropathy in Nigerians. Future studies should be considered in apparently healthy population.

This study found no relationship between central retinal artery resistive index and glomerular filtration rate, urinary albumin excretion and resistive index of the right renal artery.

\section{References}

[1] James, M.T., Hemmelgarn, B.R. and Tonelli, M. (2010) Early Recognition and Prevention of Chronic Kidney Disease. The Lancet, 375, 1296-1309. http://dx.doi.org/10.1016/S0140-6736(09)62004-3

[2] Amin, M.B., Rekha, K.P., Shegufta, F., Rahman, M.T., Abedin, N. and Mohuiddin, A.S. (2014) Resistive Index of Retinal Arterial Blood Flow in Type-II Diabetics without Retinopathy. Bangladesh Medical Journal Khulna, 47, 7-11.

[3] Kyari, F., Tafida, A., Sivasubramaniam, S., Murthy, G.V., Peto, T. and Gilbert, C.E. (2014) Prevalence and Risk Factors for Diabetes and Diabetic Retinopathy: Results from the Nigeria National Blindness and Visual Impairment Survey. BMC Public Health, 14, 1299. http://dx.doi.org/10.1186/1471-2458-14-1299

[4] Rotimi, C., Daniel, H., Zhou, J., Obisesan, A., Chen, G. and Chen, Y. (2003) Prevalence and Determinants of Diabetic Retinopathy and Cataracts in West African Type 2 Diabetes Patients. Ethnicity and Disease, 13, S2-S110.

[5] Tesfaye, S. and Gill, G. (2001) Chronic Diabetic Complications in Africa. The African Journal of Diabetes Medicine, 19, 37-40.

[6] Chandy, A., Pawar, B., John, M. and Isaac, R. (2008) Association between Diabetic Nephropathy and Other Diabetic Microvascular and Macrovascular Complications. Saudi Journal of Kidney Disease and Transplantation, $19,924$.

[7] Grunwald, J.E., Alexander, J., Ying, G.S., Maguire, M., Daniel, E., Whittock-Martin, R. and Townsend, R. (2012) Retinopathy and Chronic Kidney Disease in the Chronic Renal Insufficiency Cohort (CRIC) Study. Archives of Ophthalmology, 130, 1136-1144. http://dx.doi.org/10.1001/archophthalmol.2012.1800

[8] Klein, R., Zinman, B., Gardiner, R., Suissa, S., Donnelly, S.M., Sinaiko, A.R., et al. (2005) The Relationship of Diabetic Retinopathy to Preclinical Diabetic Glomerulopathy Lesions in Type 1 Diabetic Patients. The Renin-Angiotensin System Study. Diabetes, 54, 527-533. http://dx.doi.org/10.2337/diabetes.54.2.527

[9] Prakash, J., Lodha, M., Singh, S.K., Vohra, R. and Raja, R. (2007) Diabetic Retinopathy Is a Poor Predictor of Type of Nephropathy in Proteinuric Type 2 Diabetic Patients. The Journal of the Association of Physicians of India, 55, 412416.

[10] Basturk, T., Akcay, M., Albayrak, R., Unsal, A., Ulas, T. and Koc, Y. (2012) Correlation between the Resistive Index Values of Renal and Orbital Arteries. Kidney and Blood Pressure Research, 35, 332-339. http://dx.doi.org/10.1159/000336105

[11] Polska, E., Kircher, K., Ehrlich, P., Vecsei, P.V. and Schmetterer, L. (2001) RI in Central Retinal Artery as Assessed by CDI Does Not Correspond to Retinal Vascular Resistance. American Journal of Physiology Heart and Circulatory Physiology, 280, H1442-H1447.

[12] Hamano, K., Nitta, A., Ohtake, T. and Kobayashi, S. (2008) Associations of Renal Vascular Resistance with Albuminuria and Other Macroangiopathy in Type 2 Diabetic Patients. Diabetes Care, 31, 1853-1857. http://dx.doi.org/10.2337/dc08-0168

[13] National Kidney Foundation (2002) K/DOQI Clinical Practice Guidelines for Chronic Kidney Disease: Evaluation, Classification and Stratification.

[14] Brownlee, M. (2005) The Pathobiology of Diabetic Complications: A Unifying Mechanism. Diabetes, 54, $1615-1625$. http://dx.doi.org/10.2337/diabetes.54.6.1615 
[15] Melmed, S., Polonsky, K.S., Larsen, P.R. and Kronenberg, H.M. (2015) Williams Textbook of Endocrinology. Elsevier Health Sciences, Philadelphia.

[16] Fong, D.S., Aiello, L.P., Gardner, T.W., King, G.L., Blankenship, G., Cavallerano, J.D. and Klein, R. (2004) Retinopathy in Diabetes. Diabetes Care, 27, S84-S87. http://dx.doi.org/10.2337/diacare.27.2007.s84

[17] Arai, T., Numata, K., Tanaka, K., Kiba, T., Kawasaki, S., Saito, T. and Sekihara, H. (1998) Ocular Arterial Flow Hemodynamics in Patients with Diabetes Mellitus. Journal of Ultrasound in Medicine, 17, 675-681.

[18] Bude, R.O. and Rubin, J.M. (1999) Relationship between the Resistive Index and Vascular Compliance and Resistance. Radiology, 211, 411-417. http://dx.doi.org/10.1148/radiology.211.2.r99ma48411

[19] Saunders, H.M., Burns, P.N., Needleman, L., Liu, J., Boston, R., Wortman, J.A. and Chan, L. (1998) Hemodynamic Factors Affecting Uterine Artery Doppler Waveform Pulsability in Sheep. Journal of Ultrasound in Medicine, 17, $357-$ 368.

[20] Price, C.P., Newall, R.G. and Boyd, J.C. (2005) Use of Protein: Creatinine Ratio Measurements on Random Urine Samples for Prediction of Significant Proteinuria: A Systematic Review. Clinical Chemistry, 51, 1577-1586. http://dx.doi.org/10.1373/clinchem.2005.049742

[21] Mitchell, S.C.M., Sheldon, T.A. and Shaw, A.B. (1993) Quantification of Proteinuria: A Re-Evaluation of the Protein/Creatinine Ratio for Elderly subjects. Age Ageing, 22, 443-449. http://dx.doi.org/10.1093/ageing/22.6.443 